Research Article

\title{
Penetration of Multimedia Technology in Piano Teaching and Performance Based on Complex Network
}

\author{
Yitian Niu \\ School of Music, Liaoning Normal University, Dalian, Liaoning 116000, China \\ Correspondence should be addressed to Yitian Niu; didiniu722@lnnu.edu.cn
}

Received 2 September 2021; Revised 6 October 2021; Accepted 15 October 2021; Published 1 November 2021

Academic Editor: Sang-Bing Tsai

Copyright ( $) 2021$ Yitian Niu. This is an open access article distributed under the Creative Commons Attribution License, which permits unrestricted use, distribution, and reproduction in any medium, provided the original work is properly cited.

\begin{abstract}
Multimedia network teaching, as a modern teaching mode, provides an opportunity for the establishment of new educational methods and creates conditions for the all-round expansion of educational functions. This article mainly studies the penetration analysis of complex network and multimedia technology to piano teaching and performance. This article introduces complex network and multimedia technology into piano teaching cases to classify, analyze, research and evaluate, remove the rough and save the essence, and screen out some typical teaching cases that meet modern learning theories, teaching requirements, and the characteristics of piano discipline. On this basis, carry forward the advantages, correct the disadvantages, and develop and design some network teaching cases for piano teachers to apply and research. Adopt a new teaching model to improve the original singleclass teaching model that focuses on teacher lectures. The new teaching mode is supported by multimedia and network technology, especially multimedia technology, which makes piano teaching move towards personalized learning, and use the method of questionnaire survey to conduct questionnaire surveys on students and teachers to investigate the impact of multimedia piano teaching. Experimental data show that, in terms of multimedia attitudes, $29.50 \%$ of teachers believe that multimedia technology is very important in piano teaching and performance, $66.10 \%$ of teachers believe that multimedia technology is important in piano teaching and performance, and $4.40 \%$ of teachers believe that multimedia technology is in piano teaching and more important in performance. The experimental results show that multimedia and network technology have a good auxiliary effect on piano teaching and performance.
\end{abstract}

\section{Introduction}

Virtual Reality (VR), also known as "spiritual technology," is a simulation technology that uses computers, sensors, and various auxiliary devices to create a virtual world to reproduce the real world as much as possible. The most typical feature of virtual reality is the sense of immersion, which acts on users through sight, hearing, and touch to make them feel immersive. With the advent of the information age with multimedia and computer network as the core, the development and popularization of multimedia and network technology are rapidly extending to the field of education [1]. Using the immersion of virtual reality can better teach piano and improve the quality of teaching. The introduction of multimedia and network technology in piano teaching not only promotes the transformation of teaching methods and methods, but also greatly expands students' vision and stimulates students' interest in learning piano.

Multimedia teaching, as a new auxiliary tool, innovates and changes piano teaching and promotes students to better master the basic knowledge of piano courses. It can promote students to effectively master the basic theories and performance techniques of piano. Moreover, traditional piano teaching methods can no longer meet the actual needs of the times and students, so the full use of new concepts in multimedia piano teaching can better promote the development of teaching. Combining the latest educational concepts of teaching under multimedia and network technology, through a representative classroom teaching design, the current multimedia and network technology is applied to the four teaching modes of piano classroom teaching to investigate, analyze, and compare. The advantage of the role 
of serving in teaching, applied to the classroom, improves learning efficiency $[2,3]$. It is hoped that through this research, a targeted and reference-valued research material will be provided for the smooth implementation of the integration of multimedia and network technology and piano courses. The study of this problem has strong practical value and practical significance. At the same time, studying this problem has a good guiding role in deepening the reform of piano teaching and improving teaching efficiency $[4,5]$.

At present, many scholars have made more in-depth research on piano teaching and performance. Chen studies how to integrate multimedia and piano performance and popularize it. He believes that the comprehensive application of network platforms and multimedia provides a new model for modern piano teaching and performance. He optimized and analyzed the modern piano performance based on the multimedia system. In the process of playing the piano, pianists should continue to improve relevant requirements through scientific and rigorous training. The use of digital piano classrooms for teaching can greatly improve the effect of piano skill training and help optimize and improve the quality of music education. However, the conclusions of his research are not supported by data and are not rigorous enough [6]. Liu and Zhang believe that the rapid development of network technology provides a new platform for college piano teaching. They analyzed the optimized application of network resources in university piano teaching reform under the background of entrepreneurial education [7]. The purpose of Zhang's research is to extract music characters through audio signal processing and feature selection so that they can be used for music analysis, classification, and automatic score recording. In order to use the computer to describe the piano musical characters, he combined multimedia, signal processing, and pattern recognition technology with music theory so that the computer imitated the human evaluation of piano performance. His work belongs to the research field of music recognition theory and its application. Using audio signal analysis and processing, the computer can identify musical characters and evaluate their performance. He first outlined the concept and framework of an automatic piano performance evaluation system based on music recognition theory. Then, implement the evaluation system through performance testing. Based on music theory and the physical properties of musical notes, seven musical characteristics are proposed for recognition [8]. Zhukov et al. evaluated a new course for training advanced pianists' audiovisual skills, which combines three teaching strategies that have proven effective in earlier studies. The course was developed collaboratively and tested in two implementation methods. Pretest and posttest were performed on 25 participants, and their games were analyzed using customized software [9]. Armenteros uses multimedia teaching materials as learning tools to understand different behavioral intentions. To achieve this goal, he proposed a research model that includes perceived usefulness, perceived ease of use, perceived enjoyment, perceived self-efficacy, multimedia teaching, previous technical experience, and self-paced learning. These variables are taken from previous educational technology research. In these models, he mainly considers technology acceptance models, motivation models, and social cognitive theories. In order to assess the relationship between the structures, he conducted an analysis based on structural equation modeling (SEM), especially partial least squares (PLS). The research results confirm that students are willing to use multimedia teaching materials to help them learn.

The main innovative work of this paper includes the following aspects: (1) through data combining and analysis, find out the problems encountered by multimedia in the actual piano classroom, and put forward targeted solutions. According to the questionnaire, interview outline, and classroom observation table, summarize the common problems reflected by the teachers and students of the three semesters, proceed from the overall situation, analyze the reasons behind the problems, and formulate corresponding countermeasures. (2) Multithreaded methods are used to realize the recording, subcontracting, storage, and release of learning resources. Using object-oriented programming ideas and the realization mechanism of the bridge structure, the realization of hierarchical structure, class encapsulation, and multibit changes.

\section{Application of Complex Network and Multimedia Technology to Piano Teaching and Performance}

\subsection{Complex Network}

2.1.1. The Formation and Development of Complex Networks. With the rapid development of Internet technology and communication technology, human society has thus entered the "network age." The network has penetrated into all aspects of people's lives. The shadow of the network can be seen everywhere in life, such as transportation network, electric power network, teaching system network, and the individual as an individual is also an important component of various social network [10]. Research on complex networks can measure network connectivity and ensure the stability and reliability of multimedia teaching networks. Complex networks originated in the early eighteenth century and were mainly used in graph theory and topology in the field of mathematics. Later, with the development of technology, the research on complex networks became more and more in-depth. Since the end of the last century, the research on complex networks has entered a boom stage and continues to this day. Complex network has the characteristics of irregularity and complexity. It is a network structure composed of nodes and complex interconnection relationships between nodes. It is formed by interconnecting different nodes. The nodes represent the basic components of the system, and the edges are connected. The strength of the relationship between the nodes of the network is different. It is very necessary to redefine a new metric to express and distinguish the different relationships between nodes and nodes represent the interactive relationship between the units [11]. 
2.1.2. The Nature of Complex Networks. Complex networks generally have the following characteristics:

(1) They are overall sparse and locally dense.

(2) They have no scale characteristics.

(3) They have the characteristics of a small world [12].

2.1.3. Complex Network Classification. First, according to the types of real networks, complex networks can be divided into social networks, information networks, technical networks, and biological networks. These four network structures are different, but all have the same network characteristics. The role of network nodes between them is very complicated and very irregular, and the differences between nodes in terms of network feature metrics such as degree and clustering coefficient are very large $[13,14]$.

Second, according to the degree distribution characteristics of real network nodes, complex networks can be divided into random graph models, small world models, scale-free models, and large unified hybrid models [15].

2.1.4. Complex Network Structure. Complex networks have undergone an evolution from a regular network to an irregular network. The earliest regular network consists of simple nodes and nodes, and its network structure is relatively simple. With the advancement of network technology, more and more complex structural systems have been developed and formed an irregular complex network [16]. The complex network model is between completely regular and completely random and presents the statistical characteristics of small world effect and scale-free. Since this network is a topological abstraction of a real complex system, it is called a complex network. Complex networks have also evolved from the earliest regular networks to more complex irregular networks. The evolution of the structure model of the complex network is shown in Figures 1 and 2.

2.1.5. Complex Network Algorithm. The complex network algorithm involves several network statistical parameters, including average shortest path, reverse average shortest path, clustering coefficient, and degree distribution. The specific algorithm is as follows:

Step 1. Let network $G=(V, \varepsilon), V$ be the set of nodes in the network, and $\varepsilon$ is the set of node connection edges. The average network shortest path $d$ is an important indicator to measure network connectivity, which reflects the reliability and tightness of the network, and is defined as follows:

$$
d \equiv\langle l(v, w)\rangle \equiv \frac{1}{N(N-1)} \sum_{v \in V} \sum_{w \neq v \in V} l(v, w),
$$

where $\mathrm{d}(v, w)$ represents the shortest path length between two different nodes $v$ and $w$ in the network. The reverse average shortest path is defined as follows:

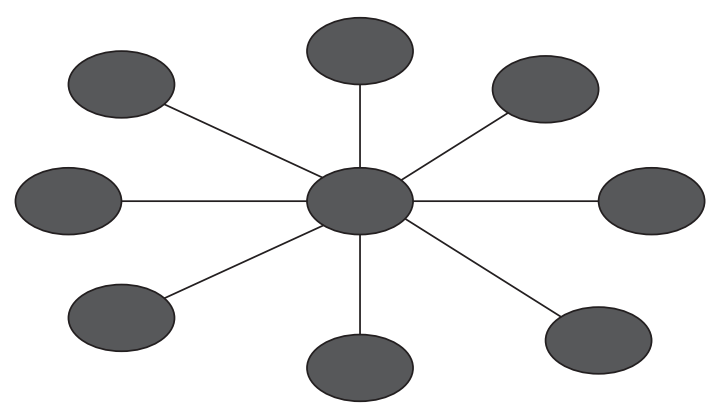

Figure 1: Complex network rule model diagram.

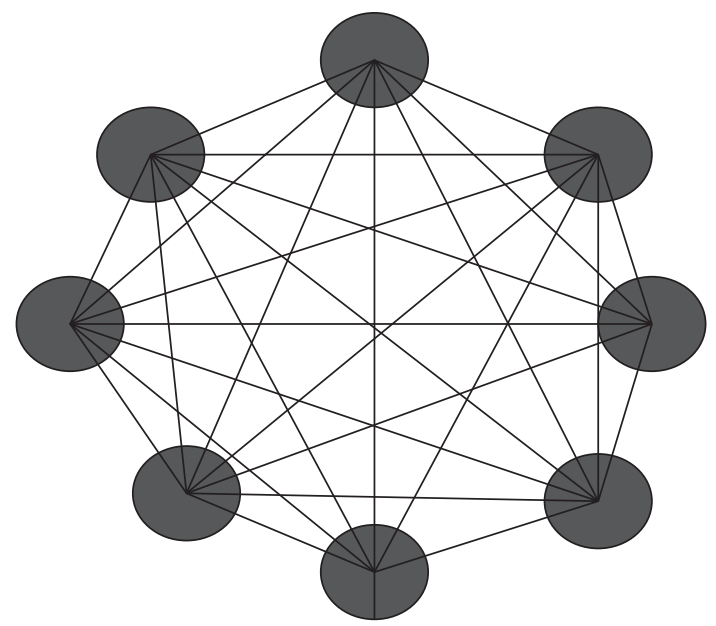

Figure 2: Complex network irregular model diagram.

$$
\mathrm{d}^{-1} \equiv\left\langle\frac{1}{l(v, w)}\right\rangle \equiv \frac{1}{N(N-1)} \sum_{v \in V} \sum_{w \neq v \in V} l(v, w) .
$$

When two different nodes cannot be connected to each other, $1 / l(v, w)=0$. It is worth noting that $d^{-1}$ is not the inverse of $d$, and the larger the value of $d^{-1}$, the better the connectivity of the network.

Step 2. Set the set of connected subgraphs of network $G=$ $(V, \varepsilon)$ to $\left\{g_{1}, g_{2}, \ldots, \ldots, g_{n}\right\}$. There are paths between any two different nodes in these subgraphs; then, the maximum connected subgraph can be defined as

$$
S=\frac{\max \left\{\left|V_{g_{1}}\right|,\left|V_{g_{2}}\right|, \ldots \ldots,\left|V_{g_{n}}\right|\right\}}{|V|} .
$$

Step 3. The network average clustering coefficient is defined as a nod $i$ has $k_{i}$ edges connecting it with other nodes. Assuming that the number of edges actually existing between the $k_{i}$ nodes is $E_{i}$, then the clustering system of node $E_{i}$ is defined as

$$
C_{i}=\frac{2 E_{i}}{k_{i}\left(k_{i}-1\right)}
$$

The average clustering coefficient of the network is defined as 


$$
C_{G \equiv(v, w)} \equiv \frac{1}{N} \sum_{V_{i} \in V, j=1}^{N} \frac{2 E_{i}}{k_{i}\left(k_{i}-1\right)} .
$$

Step 4. Network capacity is an important indicator to measure the expected profit of the network. Let the capacity of the node $i$ be defined as

$$
\text { Value }_{i}^{t}=\sum_{\text {adj }=1}^{n} \text { ComTime }_{i \longrightarrow \text { adj }}^{t} \text {. }
$$

Among them, $\sum_{\text {adj=1 }}^{n}$ ComTime ${ }_{i \rightarrow \text { adj }}^{t}$ is the total number of calls made by node $i$ to its neighbors or the total number of short messages sent to its neighbors in time interval $t$. Then, the network capacity is the sum of the capacity of each node, and the network capacity is defined as

$$
\operatorname{NetValue}(G)=\sum_{i=1}^{N} \text { Value }_{\text {node }_{i}}^{t} \text {. }
$$

Step 5. Degree distribution: according to the classification of complex networks mentioned above, in the small world model, when the degree is $P=0$, the network will become a regular network, and when the degree $i P>0$, a nonzero $P$ value will cause the network to be disordered. Become an irregular network. For $P>0$, the degree $K_{i}$ of node $i$ can be written as $K_{i}=K / 2+c_{i}$, where $c_{i}^{1} \leq K / 2+c_{i}$ and $c_{i}^{2}=c_{i}-c_{i}^{1}$; the probability distribution for $N, c_{i}^{1}, c_{i}^{2}$ is

$$
\begin{aligned}
& P_{1}\left(c_{i}^{1}\right)=C_{K / 2}^{c_{i}^{1}}(1-p)^{c_{i}^{1}} p^{K / 2-c_{i}^{1}}, \\
& P_{2}\left(c_{i}^{2}\right)=C_{p N K / 2}^{c_{i}^{2}}\left(\frac{1}{N}\right)^{c_{i}^{2}}\left(1-\frac{1}{N}\right)^{p N K / 2-c_{i}^{2}} \equiv \frac{(p K / 2)^{c_{i}^{2}}}{c_{i}^{2} !} e^{-p K / 2} .
\end{aligned}
$$

For $K \geq K / 2$, the degree distribution should obey the following:

$$
P(k)=\sum_{n=0}^{f(k, K)} C_{K / 2}^{n}(1-p)^{n} p^{K / 2-n} \frac{(p K / 2)^{k-K / 2-n}}{(k-K / 2-n) !} e^{-p K / 2} .
$$

In the formula, $f(k, K)=\min (k-K / 2, K / 2)$.

\subsection{Multimedia Technology}

2.2.1. Application of Modern Network Technology in Education and Teaching. Technology is a historical category, and its meaning continues to evolve with the development of society. It is a combination of material props, method skills, props means, knowledge and experience, which are used to achieve the goal and naturally understand, adjust, and transform society in accordance with objective laws $[17,18]$. The definition includes two aspects, specifically, tangible important equipment, tools, means and intangible unimportant concepts, methods, skills, knowledge, and experience. The specific forms of technology will be used as teaching materials for education and educational activities [19].

Traditional education includes blackboards, chalk, and simple hanging paintings. Among the audiovisual machines, multimedia and network technology applications are the most advanced $[20,21]$. Multimedia technology refers to the comprehensive technology of computer processing, text, sound, graphics, and image transmission and playback. Multimedia computers can generate high-fidelity sounds, three-dimensional images, simulated images, video clips, and animations, which are powerful educational tools. Network technology can realize online information sharing through mutual connections between computers. The specific embodiment of the application is Internet-related service functions, such as web browsing, BBS, blog, e-mail, online video chat, search engine, and remote file transfer $[22,23]$. The evolution of teaching media technology is shown in Figure 3.

2.2.2. Virtual Reality Technology. Virtual reality technology embodies the combination of computer networks, graphics, simulation science, artificial intelligence, and other multidisciplinary technologies [24]. Virtual reality technology has the characteristics of interactivity, autonomy, immersion, multi-sensitivity, and remote display. Specifically, it has the following characteristics:

Immersion means that virtual reality technology uses computer simulation technology, graphics, artificial intelligence, and other technologies to simulate human senses. It creates a virtual reality world that makes people impossible to be different from the real world by simulating human sense of hearing, vision, touch, and smell. People cannot escape from being immersed in the virtual reality world and find comfort in the virtual reality world.

Interactivity means that the virtual reality world pays more attention to user experience. The experiencer is the protagonist and master of virtual reality technology. Humans and computers can exchange information with each other.

Autonomy means that people control their own development direction in the virtual reality world, instead of passively accepting the passively accepted plot development created by the creator of the virtual reality world. Virtual reality technology must rely on the imagination of users to construct a virtual reality space. It has reached the same unpredictable fidelity as the real society. The three major characteristics of virtual reality technology are shown in Figure 4 .

2.2.3. Image Processing Technology. In multimedia teaching, the processing and analysis of digital images is also very important. Image processing technology can process teaching images in multimedia piano teaching and provide more help for multimedia teaching. It includes image enhancement and restoration, image recognition and segmentation, and image data encoding. The virtual realitybased piano teaching process is actually a realistic simulation of the piano course, a reproduction and restoration of a real 


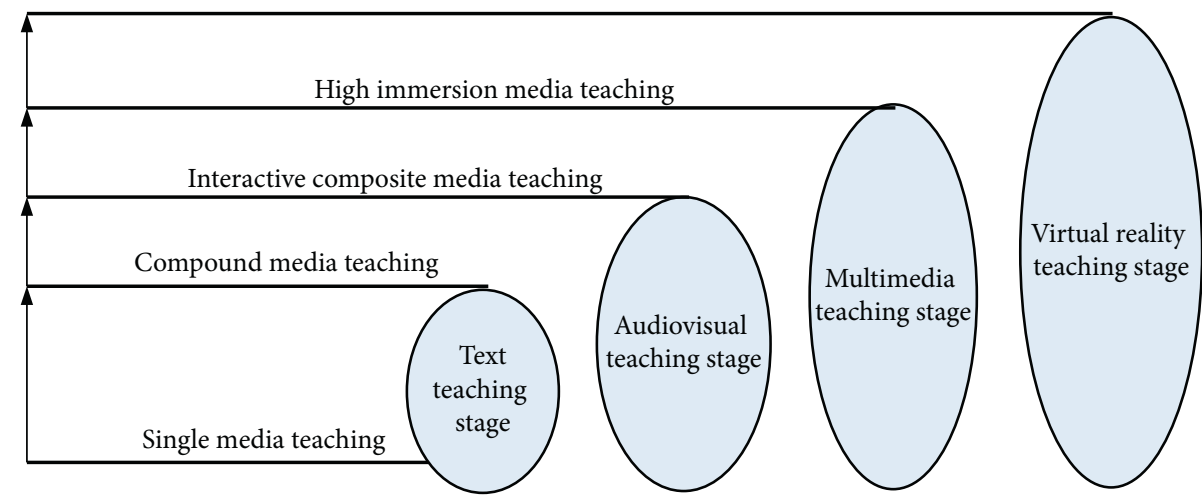

FIgURE 3: The evolution of teaching media technology.

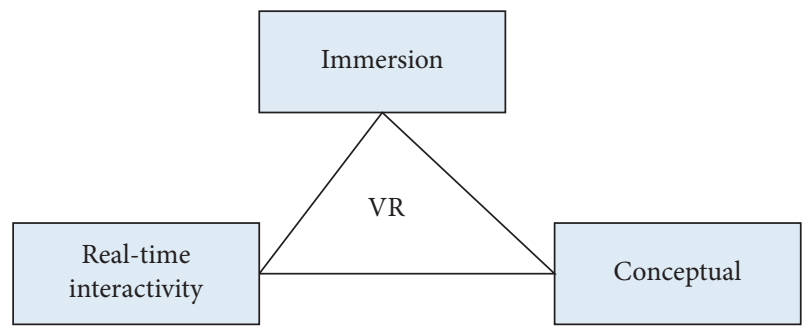

FIgURE 4: Three characteristics of VR technology.

scene, which inevitably involves the digital processing of real virtual images and situations. The key of image processing technology algorithm is image registration. Commonly used image registration methods include image registration method based on gray information, image registration method based on transform domain, and image registration method based on feature [25]. Due to the particularity of piano teaching, here we mainly introduce feature-based image registration methods. The algorithm is as follows:

(1) Find the corner points in the image window, find the feature vector of the image, set it to $T(x, y)$, take each pixel as the center, compare the gray value of each pixel in the feature vector area with the center point, and define it for

$C\left(x_{0}, y_{0} ; x, y\right)= \begin{cases}1, & \left|I\left(x_{0}, y_{0}\right)-I(x, y)\right| \leq \eta \\ 0, & \left|I\left(x_{0}, y_{0}\right)-I(x, y)\right| \leq \eta\end{cases}$

(2) Among them, $\left(x_{0}, y_{0}\right)$ represents the vector of the coordinate of the corner point in the image, $(x, y) \in T(x, y), I(x, y)$ represents the gray value at $(x, y)$, and $\eta$ represents the threshold of the gray difference. In order to strengthen the stability of the algorithm, usually $C\left(x_{0}, y_{0} ; x, y\right)$ will be defined as

$$
C\left(x_{0}, y_{0} ; x, y\right)=\exp \left\{-\left[\frac{I\left(x_{0}, y_{0}\right)-I(x, y)}{\eta}\right]^{2}\right\} \text {. }
$$

(3) Calculate the sum of all thresholds in the feature vector, and give the feature trend area

$$
S\left(x_{0}, y_{0}\right)=\sum_{(x, y) \in T(x, y)} C\left(x_{0}, y_{0} ; x, y\right)
$$

(4) The area calculated according to formula (12) reaches the minimum at the corner point, and in practical applications, the sum of the thresholds is generally compared with the set threshold

$$
R\left(x_{0}, y_{0}\right)= \begin{cases}G-S\left(x_{0}, y_{0}\right), & \text { If } S\left(x_{0}, y_{0}\right)<G, \\ 0, & \text { Otherwise. }\end{cases}
$$

(5) When the area of the region is smaller than the set threshold, the point is determined to be a corner point.

(6) Set the $(2 k+1) \times(2 k+1)$ template centered on pixel $(r, t)$ as a local window, and the sum of squares of the gray difference of adjacent pixels from four directions is

$$
\left\{\begin{array}{l}
\mathrm{d} g_{1}=\sum_{i=-k}^{k-1}\left(g_{r+i, t}-g_{r+i+1, t}\right)^{2}, \\
\mathrm{~d} g_{2}=\sum_{i=-k}^{k-1}\left(g_{r+i, t+i}-g_{r+i+1, t+i+1}\right)^{2}, \\
\mathrm{~d} g_{3}=\sum_{i=-k}^{k-1}\left(g_{r, t+i}-g_{r, t+i+1}\right)^{2}, \\
\mathrm{~d} g_{4}=\sum_{i=-k}^{k-1}\left(g_{r+i, t-i}-g_{r+i+1, t-i-1}\right)^{2} .
\end{array}\right.
$$

(7) Set the threshold value $\eta$ to get $\mathrm{CRF}_{r, t}=\min \left\{\mathrm{d} g_{1}, \mathrm{~d} g_{2}, \mathrm{~d} g_{3}, \mathrm{~d} g_{4}\right\}$, and finally select the point corresponding to the maximum response value as the corner point.

(8) Define the grayscale change $E(u, v)$ produced by the partial movement of the image window $(u, v)$ as

$$
E(u, v)=\sum_{x, y} w(x, y)[I(x+u, y+v)-I(x, y)]^{2}
$$

and then through approximate conversion 


$$
\begin{aligned}
E(u, v) & \cong[u, v] M\left[\begin{array}{l}
u \\
v
\end{array}\right], \\
M & =\sum_{x, y} w(x, y)\left[\begin{array}{cc}
I_{x}^{2} & I_{x} I_{y} \\
I_{x} I_{y} & I_{y}^{2}
\end{array}\right] .
\end{aligned}
$$

In the formula, $I_{x}$ is the gradient in the $x$-direction, and $I_{y}$ is the gradient in the $y$-direction. The corresponding function formula of the corner point is

$$
\begin{aligned}
R & =\operatorname{det}(M)-k(\operatorname{trace} M)^{2}, k=0.01 \sim 0.05, \\
\operatorname{det}(M) & =\lambda_{1} \lambda_{2}, \\
\operatorname{trace} M & =\lambda_{1}+\lambda_{2} .
\end{aligned}
$$

In the formula, if the value of $R$ is positive and large, then the point is considered a corner point.

2.3. Piano Tone Feature Extraction. When playing the piano, the player plays each note on the keyboard according to the score to form the music. The pitch corresponds to a particular key, the speed corresponds to the intensity of the keystroke, and the duration corresponds to the duration of the keystroke and release $[26,27]$. The sound effect is directly related to the correctness, intensity, and duration of the keystrokes. The essence of sound feature extraction is to determine the three indicators of intensity, duration, and whether the keys are correct.

Grasp the Strength. The intensity of the keystrokes is the size of the volume. The volume values obtained in the music score are all relative, and it is more necessary for the player to understand the music score. The volume values in the MIDI signal are absolute; yes, they cannot be calculated from the music score by formulas. The pitch value obtained by the MIDI file accounts for half of the weight, and the pitch value obtained by the piano teacher playing the MIDI keyboard against the music score accounts for half of the weight, and finally the standard MIDI pitch value is synthesized.

Duration Control. Like volume, only a relative value is obtained from the score. The processing method of extracting the duration control value when playing "tone" is the same as that of speed control value. Because the speed in music performance is not absolutely constant and the change of speed has little influence on the performance effect, the standard value of duration cannot be absolute. The standard value of instantaneous length is proportional to the total duration of the current performance.

Whether the Key Is Correct. The high characteristic of playing "sound" has only two values: equal and unequal. In order to facilitate and unify, the pitch value of MIDI file is also used to judge whether the key is correct or not.

\subsection{Multimedia Intelligent Assistant Teaching and} Demonstration. Lectures and demonstrations are teaching methods that allow students to obtain the most perceptual and intuitive information and are also the most commonly used teaching methods in piano teaching. In the one-to-one teaching of traditional piano, the use of the demonstration method can accurately demonstrate to a certain student and enhance the understanding of the demonstration actions, but it consumes more teachers' energy and the teaching efficiency is limited [28]. The emergence of digital piano group lessons has improved the efficiency of teachers' demonstrations in unit time to a certain extent. However, the teachers and students in the digital piano group class still teach in the same time and space and cannot break the time and space restrictions, and the number of times the teacher organizes a group class is limited. It is understood that the number of digital piano group lessons in general schools is once a week. The digital piano and piano group lessons of training institutions are generally twice a week. For some students with weaker comprehension ability, the demonstration once or twice a week may not enable students to master a certain technical movement, for example, the "lifting" in piano technique. When children with weak comprehension ability learn these movement essentials, the teacher often has to demonstrate repeatedly to make the students master it. It is difficult to master this movement well in piano lessons once or twice a week. Teachers often feel that under the repeated demonstrations of the teacher in class, students can standardize the movements, but after class the students themselves when practicing, there will be various problems such as deformation of the movement, too fast "lifting," and excessive movement range of the "lifting." In the next class, the teacher had to repeat the demonstration again. Most parents cannot guarantee a standardized demonstration when they supervise their students' piano practice at home. A "lifting" action becomes a "protracted battle" between the student and the teacher. In traditional piano teaching, students have certain problems in learning and mastering piano skills, such as slow learning efficiency and inability to master piano movements. The traditional teaching method is too single to meet the new diversified needs, and the effect of piano teaching is not outstanding. The intelligent piano group class is based on the digital piano, adding the function of Internet technology, breaking the time and space restrictions, and students can watch a standardized demonstration after class. Its use mainly has two functions. One is that teachers can teach real-time lessons to students far away in China through the Internet. Teachers can also use lesson recording software to record all the demonstration content within a unit time, and then play it to students in class. Online piano teaching can realize remote transmission and interaction of audio/video and cheeks. Teachers can demonstrate to students over time and space.

\section{Smart Piano Teaching Experiment}

\subsection{Experimental Environment Construction}

(1) Smart Score. Like all paper books, traditional music scores face the disadvantage of taking up too much space. A large number of music scores are usually 
difficult to carry with you. When playing, you need to take time to turn pages and even require specialized notation turners. Smart scores can help people solve this trouble perfectly. All piano tracks can be stored in an iPad-like smart product, which can be installed on the piano's music stand when playing. Smart music scores can easily retrieve the required music, and the music scores can be displayed on other largescreen display devices, and pages can be turned in synchronization with the progress of the performance when playing. Not only that, users can also create and modify music through the device.

(2) Network Piano Classroom. The piano used in the network piano classroom is neither a traditional piano nor an electronic piano, but a new type of intelligent piano with the musical functions and natural properties of a piano. It can break through the limitations of electronic pianos and traditional pianos and use network audio and video synchronization to transmit lectures so that teachers and students can get rid of the shackles of traditional time and space for language and image communication, and at the same time do not abandon the original piano touch and tone. In the online piano classroom, both teachers and students can complete all the content of the on-site teaching including demonstration and error correction. If it is a group class, the same number of pianos must be equipped on the same network.

The configuration attributes of the computers and builtin discrete graphics used in this article are shown in Table 1.

3.2. Experimental Procedure. With the combination of smart piano and traditional piano teaching, taking piano solo teaching as an example, the teaching arrangement is divided into individual lessons and group lessons. Six weeks are a systematic teaching cycle, which can be used as experimental data based on the combination of intelligent feedback from the smart piano and manual teacher feedback to summarize and analyze the course progress and quality. Smart piano group lessons will be adopted in the first and second weeks, individual smart piano lessons will be adopted in the third and fourth weeks, and traditional piano individual lessons will be adopted in the fifth and sixth weeks. Taking the example of "Chopin's Ballad in $G$ minor" as an example, teaching will start from the first week to the sixth week. The combination of students' acceptance ability, basic piano ability, and the difficulty of "Chopin's Ballad in G minor" is taken as an example. The basis is the normal stepped and complementary teaching in the teaching process. Combining the conclusions drawn from students' feedback every week, the final assessment of students' degree of completion will reflect the advantages of this new combined teaching model. In the specific experiment, the intelligent network piano lesson experience process that students participate in is shown in Figure 5.
Carefully read the smart network piano lesson requirements, virtual space scenes, and use the wearable system equipment to practice playing the piano according to the lesson requirements until the piano lesson is over.

3.3. Experimental Feedback. Through the above design, the same teaching content, different teaching methods, and teaching methods are compared. From the teaching practice data and the data and feedback of the summary table, a new teaching mode is adopted in the six-week class schedule. This is a "main + assistant," "person + instrument," and "complementary" piano teaching mode. This approach has more mobilized the enthusiasm of students, increased students' participation in the classroom, and combined the advantages of artificial and intelligent teaching. The connection of weekly courses is just right. From the feedback of students, this kind of piano teaching model of "person + device," "complementary," and "remote" can more arouse the enthusiasm of students. Students are in this teaching mode. The percentage of completion reaches $90 \%$, while the traditional teaching method is only $70 \%$. The emergence of this model is a tentative update concept of teaching based on inheriting the traditional teaching model and combining the intelligent technology of the smart piano.

3.4. Data Collection. Record various music courses through intelligent recording equipment, organize the recorded scale data, input the effective data into the computer in manual form, and finally use SPSSl3.0 software and EXCEL software to process and analyze the effective data.

\section{Penetration of Multimedia and Network Technology in Piano Teaching and Performance}

4.1. Analysis of the Concept of Playing Piano Teaching in the Environment of Multimedia and Network Technology. For data analysis, different values represent different meanings. If the average number of statistical analysis of a strategy is greater than 3, then that strategy is often used: if it is less than 3 , it means that the strategy is not often used. The standard deviation can explain the response and attitude of the respondents in the questionnaire to each surveyed strategy. When the average value is greater than 3 , the strategy is used more frequently; when the average value is less than 3 , it indicates that the strategy is used less frequently. Below, mainly use the average and standard deviation to analyze and investigate the concept of piano teaching and performance under the environment of multimedia and network technology. The specific data is shown in Table 2. Figure 6 shows the comparison of piano teaching performance concepts under multimedia and network environments.

The above results clearly show the concept of piano teaching and learning under the multimedia and network 
TABLE 1: Computer configuration used in virtual piano.

\begin{tabular}{lc}
\hline GPU & NVIDIA GeForce GTX1060 \\
CPU & Intel $^{\circledR}$ Xeon ${ }^{\circledR}$ E5-2630 \\
RAM & $16.0 \mathrm{~GB}$ \\
Video output & HDMA1.4 \\
USB port & USB3.0 port \\
Operating system & Windows 7 operating system \\
\hline
\end{tabular}

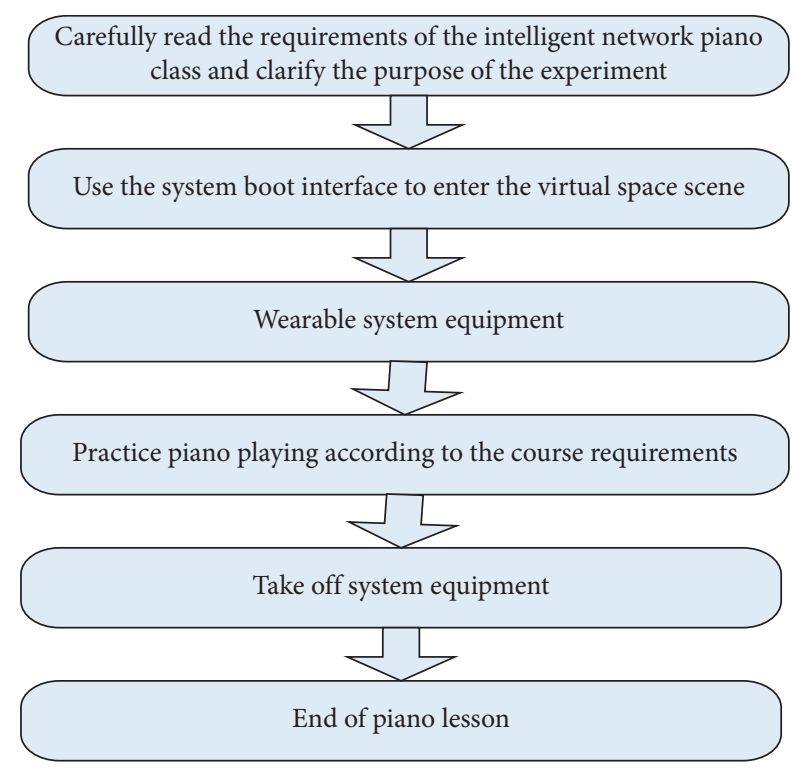

Figure 5: Flow chart of the intelligent network piano lesson experience.

TABLE 2: Piano teaching performance concepts in multimedia and network environments.

\begin{tabular}{lcc}
\hline Part A & Average & Standard deviation \\
\hline Question 1 & 3.87 & 0.42 \\
Question 2 & 2.51 & 0.38 \\
Question 3 & 3.35 & 0.85 \\
Question 4 & 4.26 & 0.63 \\
Question 5 & 3.97 & 0.13 \\
Question 6 & 3.34 & 0.29 \\
Question 7 & 2.4 & 0.73 \\
Question 8 & 2.6 & 0.39 \\
Question 9 & 2.72 & 0.82 \\
\hline
\end{tabular}

environment. Most of the average numbers supporting piano teaching performance concepts are greater than 2.5, and more than half are greater than 3 . This shows that people today are in favor of using computers to learn piano teaching and performance.

4.2. Piano Teaching and Performance Parameters. The node distribution is shown in Figure 7. A certain number of nodes are distributed in a square area. There are two types of nodes. Common nodes are small sensor nodes and do not have a positioning system, so they do not know their geographic location. The anchor node has its own GPS module and can locate its position through GPS. The common nodes are the most and the density is the greatest. In addition, there is a moderate amount of anchor nodes. Ordinary nodes complete general monitoring tasks and positioning nodes are used to help ordinary nodes perform positioning and then be used as ordinary nodes. Both types of nodes have their own communication radius, and other nodes within the communication range are called neighbor nodes and can communicate with each other. The system parameters are as follows:

Nodes_n: the number of all nodes, including anchor nodes and unlocated nodes; Anchors n: the number of anchor nodes; Square L: the side length of the area; Comm r: the communication radius of ordinary nodes, used to determine who is the neighbor; Anchor_comm r: the ratio of the communication radius of the anchor node to the ordinary node, generally 1 , if the communication radius of the anchor node needs to be increased, it can be set to other values greater than 1, such as 2. Aver nodes_num: average number of neighbors per node; Aver_anchor. nodes_num: average number of neighbor anchor nodes per node; Grid_length: grid side length, only used in simulation, the piano simulation in this article is based on multimedia network technology. The more the number of nodes, the greater the positioning accuracy. Localization error: average positioning error, which refers to the ratio of the distance from the positioning position of the node to the real position to the communication radius, and is one of the most important performance parameters of the piano. Unresolved num: the unresolved node is one of the most important performance parameters of the piano.

\subsection{Public's Attitudes towards Multimedia and Network} Technology towards Piano Teaching and Performance. Attitude is a comprehensive personal feelings and intuitive perceptions of things. This article conducts a questionnaire survey of piano teachers and students, investigating the importance of piano teachers to multimedia and the degree of students' love of multimedia teaching. The attitude of piano teachers to multimedia directly affects their use of multimedia in ordinary classroom teaching. Teachers' and students' attitudes towards multimedia are mainly reflected in the teachers' understanding of the importance of multimedia, students' preference for it, the number of times teachers use multimedia, and the main purpose of using multimedia. The specific performance is shown in Table 3. The attitude is shown in Figures 8 and 9.

In terms of multimedia attitudes, $29.50 \%$ of teachers believe that multimedia technology is very important in piano teaching and performance, $66.10 \%$ of teachers believe that multimedia technology is important in piano teaching and performance, and $4.40 \%$ of teachers believe that multimedia technology is more important in piano teaching and performance important. It can be seen that most teachers believe that multimedia is very important for piano teaching and performance, and multimedia is still supportive when entering the classroom. However, the teacher's attitude towards multimedia is not enough to explain the essence of the problem. From the survey results of students' preference 


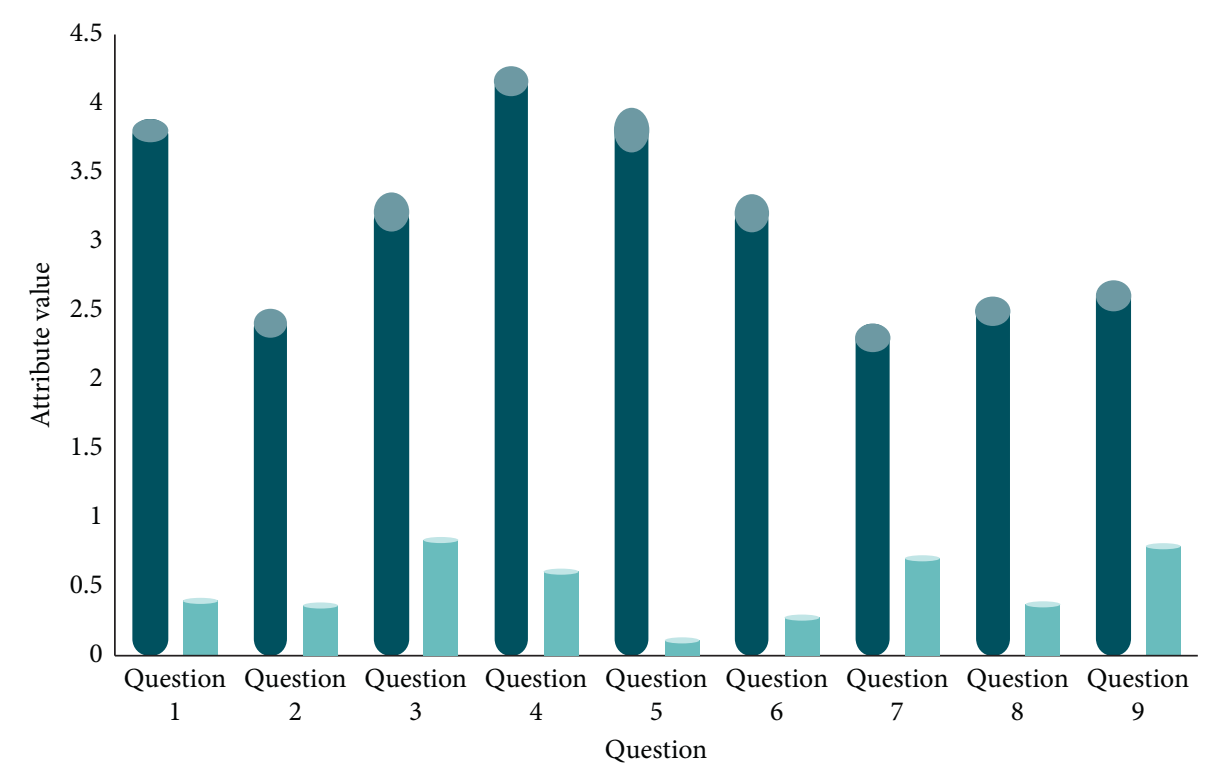

- Average

- Standard deviation

FIgURE 6: Piano teaching performance concepts in multimedia and network environment.

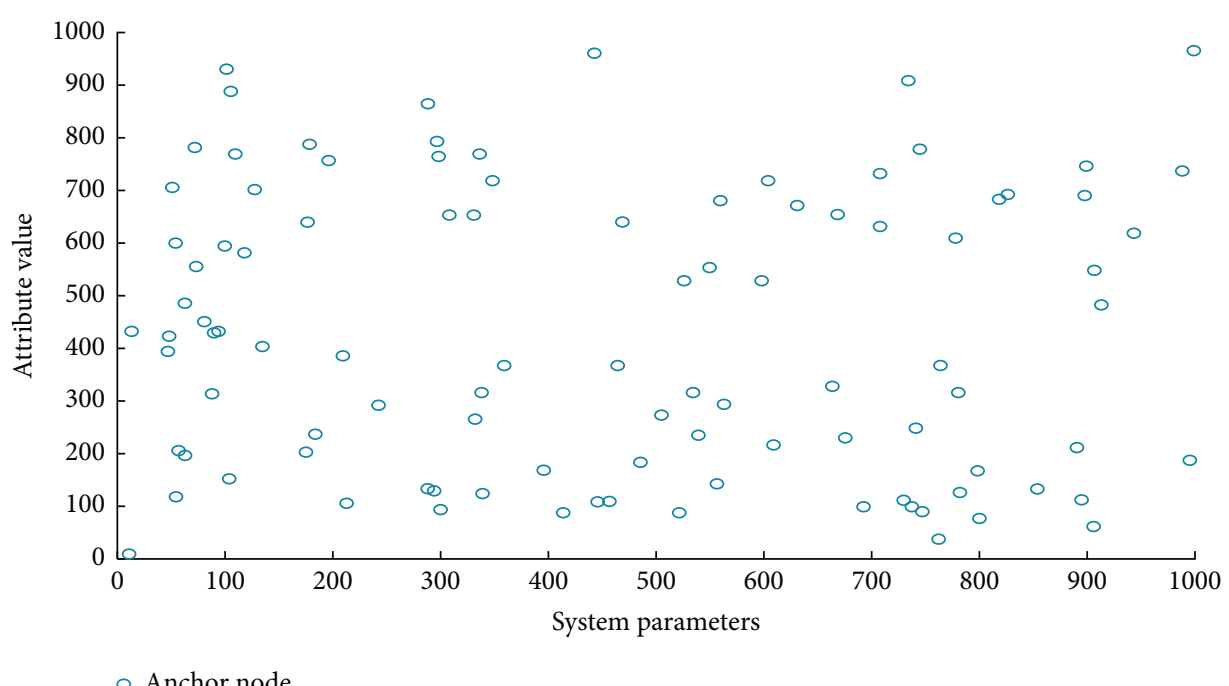

Figure 7: Node distribution diagram.

TABLE 3: The attitude of piano teachers towards multimedia.

\begin{tabular}{lccc}
\hline Topic & Options & Number of people & Percentage \\
\hline & Very important & 20 & 29.50 \\
Recognition of the importance of multimedia & Important & 45 & 66.10 \\
& More important & 3 & 4.40 \\
& Unimportant & 0 & 0 \\
\hline
\end{tabular}

for multimedia, most students still prefer teachers to use multimedia for teaching. Students are optimistic about multimedia piano teaching. They believe that multimedia piano teaching can better improve their piano performance. The specific performance is shown in Table 4 . The percentage of students' preference for multimedia teaching is shown in Figures 10 and 11.

From Table 4 and Figures 10 and 11, it can be seen that $85.5 \%$ of the students still prefer multimedia; only 5 students dislike the use of multimedia by teachers, and these 5 


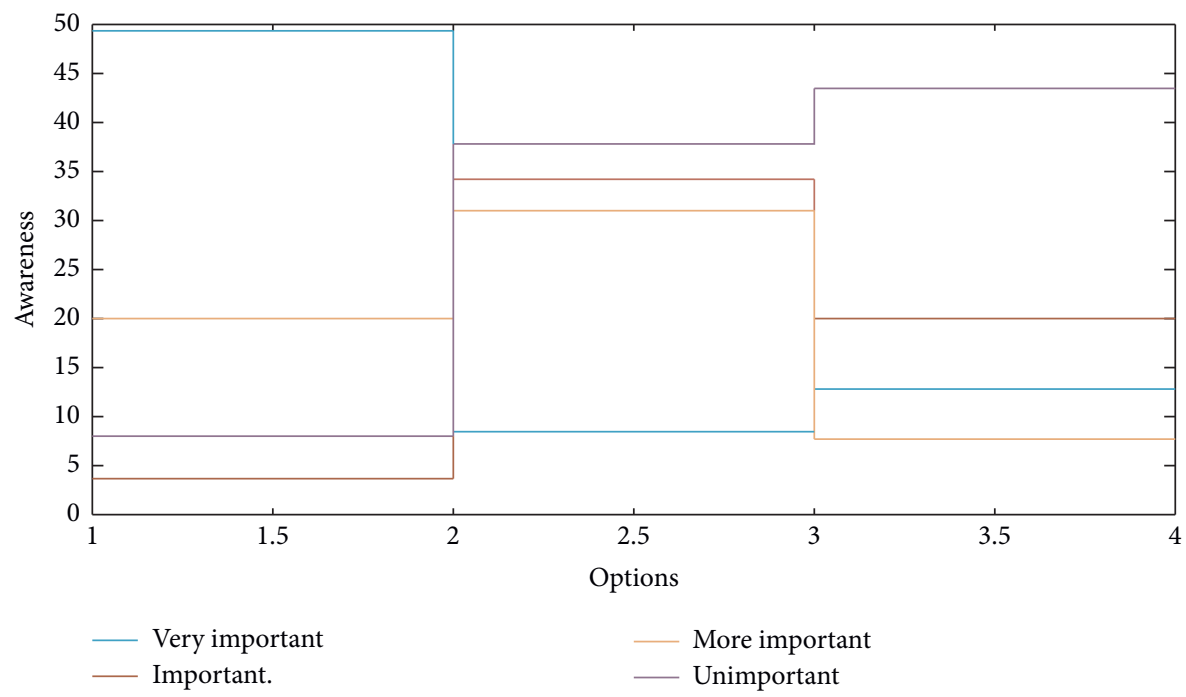

FIgURe 8: Piano teacher's attitude towards multimedia teaching.

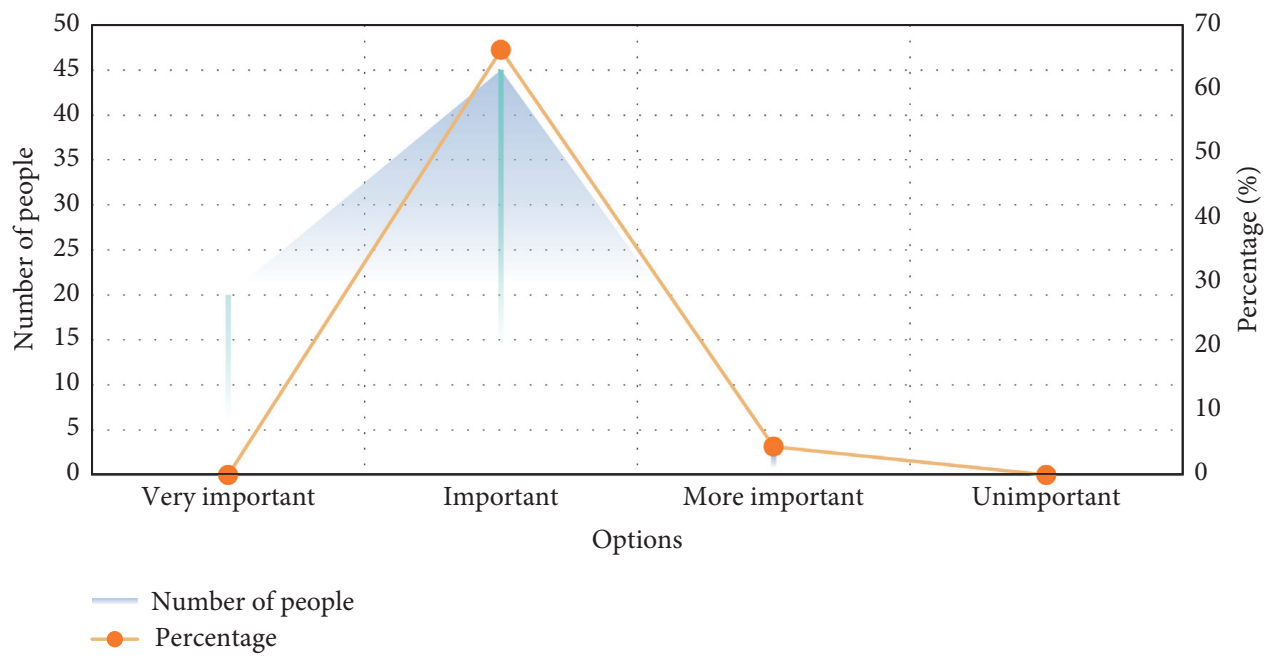

FIgUre 9: Piano teacher's attitude towards multimedia teaching.

TABle 4: How much students like multimedia teaching.

\begin{tabular}{lccc}
\hline Topic & Options & Number of people & Percentage \\
\hline & Like very much & 105 & 56.9 \\
How much do students like multimedia & Quite like it & 52 & 28.6 \\
& Does not matter & 26 & 14.8 \\
& Dislike & 5 & 2.7 \\
\hline
\end{tabular}

students are all lower-grade students, which may be related to their familiarity with multimedia. The degree is related. In the lower grades, due to their limited cognitive abilities and lack of comprehensiveness and depth in their cognition of things, their thinking is at the stage of specific calculations, mainly relying on external and superficial things to judge things, and then determine their own preferences, so these five students may have made their judgments based on ignorance of multimedia. In the process of piano teaching, teachers need to pass to students not only performance skills, but also how to feel the artistic information and emotions conveyed in piano performance. Every teaching is of special significance to teachers. It can be seen from the above that most teachers believe that multimedia technology is important in piano teaching and performance. This is consistent with most students' preference for multimedia. It is precisely because students prefer multimedia technology that teachers are encouraged to use multimedia in class teaching so it is of practical significance to study the application status of 


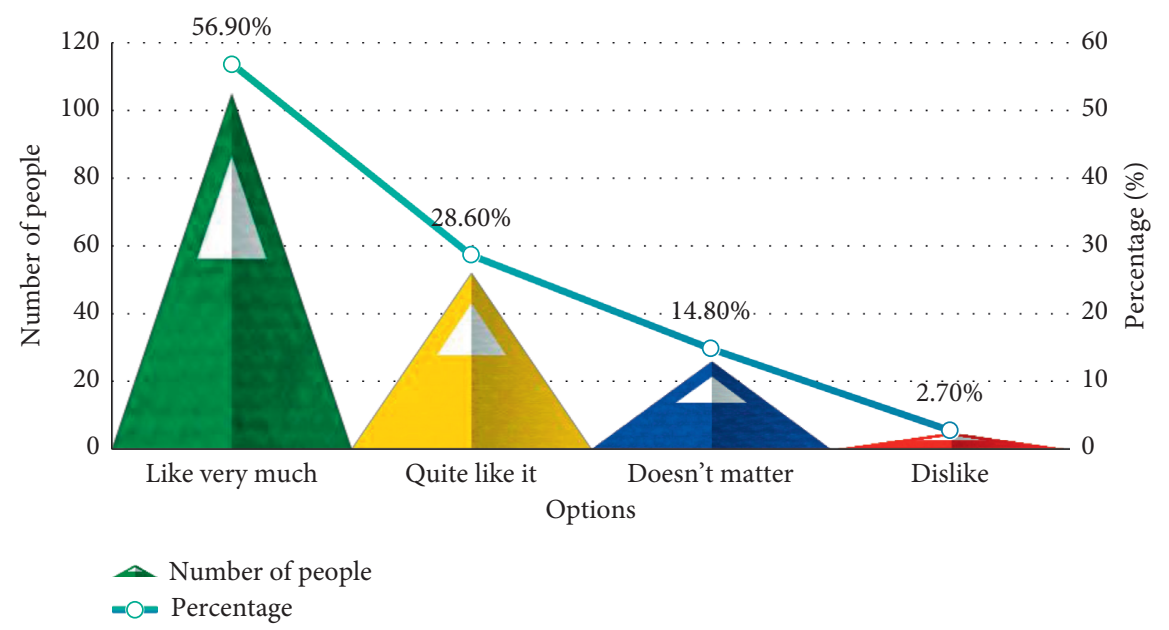

FIgURE 10: How much students like multimedia teaching.

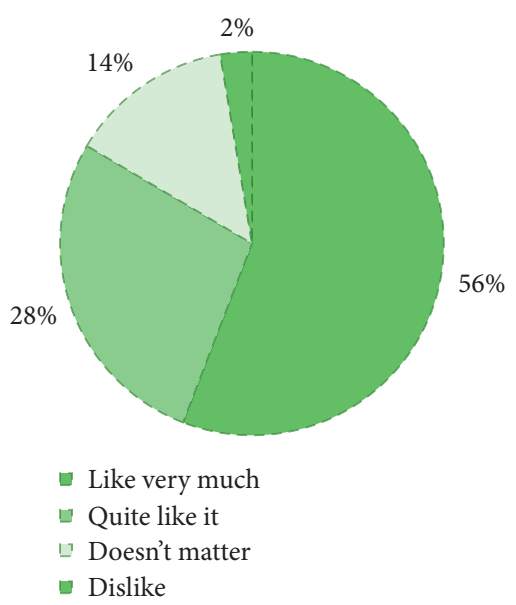

FIgURE 11: Percentage of students like multimedia teaching.

multimedia technology in piano teaching and performance.

\section{Conclusions}

This study expounds the related concepts and characteristics of multimedia network teaching technology and summarizes the composition, classification, development status, and trend of multimedia network teaching system based on multimedia technology. From the two aspects of the organization of teaching content and the application of streaming media, the key technologies used in the design of the network teaching system are explained. According to the idea of dividing teaching components, the various subsystems of the streaming teaching system are reasonably divided, and several types of technical problems that need to be solved when applying multimedia to the system are analyzed. This article designs a multimedia network teaching system. The system relies on multimedia network technology, utilizes existing campus network facilities, and uses pure software to provide teaching services for teachers and students.
This study's use of multimedia network technology and classroom teaching can enhance the teaching effect and form a relaxed teaching environment that is conducive to students' independent learning and cooperative inquiry. Secondly, the problems in the teaching process of this article are mainly reflected in the three levels of teachers, students, and school management. It is proposed to fully understand the teaching functions of multimedia network technology, build a capable multimedia network teaching and management team, give full play to the positive functions of the school network teaching platform, and establish the multimedia network teaching mechanism necessity.

\section{Data Availability}

The data that support the findings of this study are available from the author upon reasonable request.

\section{Disclosure}

The author received no financial support for the research, authorship, and/or publication of this article.

\section{Conflicts of Interest}

The author declares no potential conflicts of interest with respect to the research, authorship, and/or publication of this article.

\section{References}

[1] S. Sun, M. Kadoch, L. Gong, and B. Rong, "Integrating network function virtualization with SDR and SDN for 4G/5G networks," IEEE Network, vol. 29, no. 3, pp. 54-59, 2015.

[2] M. E. C. Zuta, J. C. A. Quijano, and F. P. Alvino, "Cultural identity and teaching performance in educational institutions," Opción, vol. 33, no. 84, pp. 292-322, 2017.

[3] Y. Zhang, Q. He, Y. Xiang et al., "Low-cost and confidentiality-preserving data acquisition for internet of multimedia things," IEEE Internet of Things Journal, vol. 5, no. 5, pp. 3442-3451, 2017. 
[4] P. Zhao, "An optimized ability model construction of skill training in piano performance teaching," Revista de la Facultad de Ingenieria, vol. 32, no. 9, pp. 636-641, 2017.

[5] D. Feng, "Research on track and field training system based on network technology," International Journal of Multimedia and Ubiquitous Engineering, vol. 11, no. 1, pp. 407-416, 2016.

[6] L. Chen, "An optimization analysis of modern piano playing mode based on ultimedia system," Boletin Tecnico/technical Bulletin, vol. 55, no. 11, pp. 519-525, 2017.

[7] C. Liu and Q. Zhang, "Optimized application of network resources in college piano teaching reform under the background of innovation and entrepreneurship education," Boletin Tecnico/Techniscal Bulletin, vol. 55, no. 8, pp. 225-231, 2017.

[8] Y. Zhang, "Application of fuzzy neural network in music recognition," Revista de la Facultad de Ingenieria, vol. 32, no. 6, pp. 171-180, 2017.

[9] K. Zhukov, L. Viney, G. Riddle, A. Teniswood-Harvey, and K. Fujimura, "Improving sight-reading skills in advanced pianists: a hybrid approach," Psychology of Music, vol. 44, no. 2, pp. 155-167, 2016.

[10] Y. Auh and H. R. Sim, "Uses of social network topology and network-integrated multimedia for designing a large-scale open learning system: case studies of unsupervised featured learning platform Design in South Korea," Multimedia Tools and Applications, vol. 78, no. 5, pp. 5445-5462, 2019.

[11] S. E. Chang, W.-C. Shen, and C.-H. Yeh, "A comparative study of user intention to recommend content on mobile social networks," Multimedia Tools and Applications, vol. 76, no. 4, pp. 5399-5417, 2017.

[12] C. Yao, J. Xiao, T. Tillo, Y. Zhao, C. Lin, and H. Bai, “Depth map down-sampling and coding based on synthesized view distortion," IEEE Transactions on Multimedia, vol. 18, no. 10, pp. 2015-2022, 2016.

[13] E.-S. Nahm, "Design of network protocol based on P2P collaboration and user's content using information," The Transactions of the Korean Institute of Electrical EngineersThe Transactions of the Korean Institute of Electrical Engineers, vol. 66, no. 3, pp. 575-580, 2017.

[14] J. A. López-López, S. R. Davies, D. M. Caldwell et al., "The process and delivery of CBT for depression in adults: a systematic review and network meta-analysis," Psychological Medicine, vol. 49, no. 12, pp. 1-11, 2019.

[15] L. Jiarong, Z. Ning, and Y. Long, " $\mathrm{t} / \mathrm{k}$ fault diagnosis algorithm of n-dimensional hypercube network based on the MM * model," Journal of Systems Engineering and Electronics, vol. 29, no. 01, pp. 220-226, 2018.

[16] Y. Yanli and Z. Li, "Research on application of network information technology in landscape technology practice teaching," Agro Food Industry Hi-Tech, vol. 28, no. 1, pp. 1039-1043, 2017.

[17] L. Sun, "Research on influence of multimedia network teaching platform and effective interaction on physical education curriculum based on smart classroom," International Journal of Smart Home, vol. 10, no. 11, pp. 165-176, 2016.

[18] D. Yang, D. Lu, and J. Dong, "Research on the ideological education of college students based on multimedia technology and cloud service platform," Revista de la Facultad de Ingenieria, vol. 32, no. 1, pp. 504-510, 2017.

[19] Y. Liu, J. Yang, B. Guo, J. Yang, and X. Zhang, "A novel image segmentation combined color recognition algorithm through boundary detection and deep neural network," International Journal of Multimedia and Ubiquitous Engineering, vol. 11, no. 2, pp. 331-342, 2016.
[20] L. Xu, "Study on multimedia teaching and the reform of college physical education: evaluation of teaching effect," International Journal of Security and its Applications, vol. 10, no. 2, pp. 255-266, 2016.

[21] Y. Guo and Q. Li, "AoIP / AVB Technology and Application of Digital Audio Networ," International Journal of Multimedia and Ubiquitous Engineering, vol. 11, no. 5, pp. 305-318, 2016.

[22] M. U. Ashraf, fnm au, S. Arif, A. Basit, and M. S. Khan, "Provisioning quality of service for multimedia applications in cloud computing," International Journal of Information Technology and Computer Science, vol. 10, no. 5, pp. 40-47, 2018.

[23] C. Li, Z. Zhang, and L. Zhang, "A novel authorization scheme for multimedia social networks under cloud storage method by using MA-CP-ABE," International Journal of Cloud Applications and Computing, vol. 8, no. 3, pp. 32-47, 2018.

[24] J. Montalban, P. Scopelliti, M. Fadda et al., "Multimedia multicast services in 5G networks: subgrouping and nonorthogonal multiple access techniques," IEEE Communications Magazine, vol. 56, no. 3, pp. 91-95, 2018.

[25] M. Jalil Piran, N. H. Tran, D. Y. Suh, J. B. Song, C. S. Hong, and Z. Han, "QoE-driven channel allocation and handoff management for seamless multimedia in cognitive $5 \mathrm{G}$ cellular networks," IEEE Transactions on Vehicular Technology, vol. 66, no. 7, pp. 6569-6585, 2017.

[26] P. Di and L. Hongye, "Research and application of multimedia teaching in college physical education," Agro Food Industry Hi-Tech, vol. 28, no. 1, pp. 339-342, 2017.

[27] J. M. Andrew, "Teaching for transfer of second language learning," Language Teaching, vol. 51, no. 03, pp. 330-348, 2018.

[28] J. N. Killian, "On knowns and unknowns of cultural diversity," Journal of Music Teacher Education, vol. 25, no. 3, pp. 7-11, 2016. 